\title{
The influence of process gas type on the enamel surface condition of a high power diode laser generated single- stage ceramic tile grout seal
}

\author{
J. Lawrence*, L. Li*, R.E. Edwards** and A.G. Gale** \\ *Laser Processing Research Centre, Manufacturing Division, Department of Mechanical \\ Engineering, ${ }^{* *}$ Department of Civil and Construction Engineering, University of Manchester \\ Institute of Science and Technology (UMIST), Manchester, M60 1QD, UK.
}

\section{Correspondence}

Dr. Jonathan Lawrence

Manufacturing Engineering Division,

School of Mechanical \& Production Engineering,

Nanyang Technological University (NTU),

Nanyang Avenue,

Singapore 639798.

Tel : $(+65) 67905542$

Fax : (+65) 67911859

e-mail : mjlawrence@ntu.edu.sg 


\begin{abstract}
Almost all laser materials processing operations require the simultaneous use of an process or assist gas. This paper examines the use of $\mathrm{O}_{2}, \mathrm{Ar}, \mathrm{N}_{2}$ and $\mathrm{He}$ as process gasses during the firing of a vitreous enamel to form a single-stage ceramic tile grout seal with a high power diode laser (HPDL) and the effects thereof on the surface condition of the glaze. The findings revealed marked differences in the surface condition of the HPDL generated enamel glaze depending upon the process gas used. The use of $\mathrm{O}_{2}$ as the process gas was seen to result in glazes with far fewer microcracks and porosities than those generated with any of the other three gasses, particularly He. Such differences were found to be due to the ability of the smaller $\mathrm{O}_{2}$ gas molecules to dissolve molecularly into the open structure of the HPDL generated enamel glaze and also, the inherent reactiveness of $\mathrm{O}_{2}$ which consequently effects exothermic reactions when it is used as a process gas. Both occurrences were seen, in turn, to affect the cooling rate and therefore the tendency of the molten glaze to generate microcracks when cooled.
\end{abstract}

Keywords: High power diode laser (HPDL); Ceramic; Tile; Grout; Gas; Glaze 


\section{Introduction}

Despite the obvious benefits and advantages that ceramic tiled surfaces can yield, a number of attendant problems nevertheless exist. In particular, the most prominent problem is that contaminants can enter into, and exit a space via the grout used to fill the void between adjoining ceramic tiles. What is more, routine cleaning of the tiled surface with detergents, etc. brings about a significant reduction in the life of the epoxy tile grout as they are very difficult to clean and become contaminated over time and have to removed physically or mechanically, both of which are arduous and costly undertakings. To alleviate these problems associated with commercially available epoxy tile grout, a new approach was created by Lawrence et al. [1-3]. This new approach not only comprised of the development of a new grout material termed the amalgamated oxide compound grout (AOCG), but also a new grouting technique whereby a high power diode laser (HPDL) was used to glaze an enamel coating on the surface of the AOCG, thus resulting in a two-stage sealing process. This technique has been developed further by Lawrence et al. [4], resulting in the development of a single-stage sealing process using the HPDL. The new grouting material used crushed vitrified ceramic tiles as a bulk filler with an enamel frit placed directly on top. In this way a single-stage process could be achieved as theoretically the materials could be applied in a single action and only one pass of the HPDL would be required. The seals generated between adjoining vitrified ceramic tiles with the single-stage grout were found to be tough and inexpensive, as well as providing an amorphous, crack-free surface glaze. In this way the tiles were sealed together permanently, preventing any further contamination activity; in effect creating a completely sealed surface that is both impermeable and relatively simple to clean and maintain since contaminants are basically arrested on the surface of the tile and the glazed seal. Because such a seal would be an integral a part of the surface as the tiles themselves, the necessity to remove old or contaminated grout from the void between the tiles would be eliminated.

Porosity and microcracking are attendant problems when laser treating the surface of many materials, with the enamel glaze investigated in this study being no exception. It is known, however, that certain process gasses can go some way to assuage or even eliminate the serious problems of surface porosity and microcracking. To this end, work was conducted in order to elucidate the effects of using $\mathrm{Ar}, \mathrm{O}_{2}$ $\mathrm{N}_{2}$ and $\mathrm{He}$ process gasses during the glazing of the enamel surface of the single-stage ceramic tile 
grout seal with a HPDL. The findings showed a marked difference existed in the surface condition of the concrete after HPDL treatment depending on the process gas used.

Investigations into the effects of different process gasses during the laser processing of materials have hitherto focused mainly on the laser welding and cutting of steels, with other studies examining the laser ablation drilling and surface treatment of numerous metals. These studies have revealed the high degree of influence that the process gas employed has on the process and end results. In both $\mathrm{CO}_{2}[5$, 6] and Nd:YAG [7] laser welding of carbon steels it has been observed that greater penetration can be achieved if $\mathrm{He}$ is used, whilst faster welding rates can be realised if $\mathrm{Ar}$ is used. Chung et al [8] concluded that such benefits as increased penetration depth and faster welding speed arising from appropriate process selection during laser welding and cutting were due in part to the gasses' ability, or lack of it, for removing plasma plumes. In a study into the influence of process gas type on the surface characteristics of the welds generated on steel with a $\mathrm{CO}_{2}$ laser, Qiang et al. [9] found that the process gas type significantly affected the surface morphology of the welds. To date, a number of workers have reported on the effects of process gasses during laser drilling [10-14]. In particular, detailed studies by Low et al. $[13,14]$ revealed that, whereas the use of an $\mathrm{O}_{2}$ process gas typically caused increased liquid particle ejection coupled with volatile burning, the use of an Ar process induced material ejection predominantly by bulk radial liquid ejection.

\section{Development of the single-stage ceramic tile grout}

Commercially available epoxy tile grout is currently formulated from four main components: acrylic emulsion, limestone, dolomite and a cellulose substance. It is well established that glazing can only be achieved using materials containing at least some of the essential glass network forming compounds such as $\mathrm{SiO}_{2}$ and $\mathrm{BO}_{3}$, along with some glass network modifying and intermediate compounds such as $\mathrm{Na}_{2} \mathrm{O}, \mathrm{Al}_{2} \mathrm{O}$ and $\mathrm{MgO}$ [15]. As such, it proved impossible to directly glaze epoxy tile grouts [1-3]. Also, the coating of epoxy tile grout with a vitrifiable substance was not possible since the actual bonding mechanism by which the grout adheres to surfaces to which it is applied is mechanical, or more precisely hydraulic, and is achieved as a result of the acrylic emulsion hydraulically bonding to the surface [16]. Since the grout does not bond to surfaces chemically, it is unable to withstand elevated temperatures. Indeed, at temperatures above $200^{\circ} \mathrm{C}$ the grout will 
actually de-bond from the surface it is applied to [17], a temperature well below the softening point of commercial vitreous coating materials.

Based on the findings of previous work conducted by Lawrence et al. [1-3] in which a two-stage ceramic tile grout sealing process was developed, research was undertaken to devise a single-stage process [4]. But initial attempts to generate a single-stage seal using a selection of oxide compound powders and a commercially available enamel frit consistently resulted in unsatisfactory glazes, with microcracking and porosity generation to varying degrees, as well as inconsistent glazing being ever present features. However, the adoption of a new approach yielded more acceptable results. Whereas previously the compounds and the enamel frit were combined together to form a single amalgamated mixture, the new approach specifically kept the compounds and the enamel frit apart. Yet work conducted previously by Lawrence et al.[1-3, 18, 19] revealed that in order for the enamel frit to wet and bond to the compound mixtures, HPDL surface treatment of the compound mixtures was necessary (so as to generate a vitrified surface) prior to the application of the enamel frit. The solution found for this problem was to use crushed vitrified ceramic tiles as a bulk filler, since the enamel frit will readily wet this material without the need for prior HPDL surface treatment, with the enamel frit placed directly on top as shown in Fig. 1. In this way a single-stage process could be achieved as theoretically the materials could be applied in a single action and only one pass of the HPDL would be required.

\section{Experimental procedures}

The experiments were carried out using UK standard $150 \times 150 \times 5 \mathrm{~mm}^{3}$ vitrified ceramic tiles of various colours: white, navy blue, leaf green and jet black, cut into smaller pieces, $20 \times 20 \mathrm{~mm}^{2}$, for experimental purposes and applied in pairs to an ordinary Portland cement (OPC) substrate using standard epoxy tile grout (Vallance Ltd). The spacing between the vitrified edges of each tile pair was the industry recommended $1.5 \mathrm{~mm}$. The fixed ceramic tile pieces were then allowed to set for the standard setting time of one day. Vitrified ceramic tiles were crushed and fine ground using a pestle and mortar and then sieved to ensure a particle size of less than $45 \mu \mathrm{m}$. So as to form a manageable paste, the vitrified ceramic tile powder was mixed with approximately $50 \mathrm{wt} \%$ water diluted sodium

silicate solution. The vitrified ceramic tile paste was then placed into the void, flush to the surface of 
the tiles and allowed to cure for $8 \mathrm{~h}$. The set mixture was then overlaid directly with a thin layer $(500 \mu \mathrm{m})$ of enamel frit (Ferro Group (UK) Ltd.) which, in order to form a manageable paste, was mixed with $20 \mathrm{wt} \%$ white spirit. The composition of the enamel consisted mainly of the following: $\mathrm{SiO}_{2}, \mathrm{~B}_{2} \mathrm{O}_{3}, \mathrm{Na}_{2} \mathrm{O}, \mathrm{Mn}$ and small quantities of $\mathrm{Ba}, \mathrm{Al}_{2} \mathrm{O}_{3}$ and $\mathrm{Ni}$, whilst the powder size was approximately $25 \mu \mathrm{m}$. The enamel frit paste was allowed to cure for $1 \mathrm{~h}$ whereupon it was irradiated immediately with the defocused HPDL beam.

The laser employed in this work was a HPDL (Diomed Ltd.) emitting at $810 \mathrm{~nm} \pm 20 \mathrm{~nm}$ with a maximum output power of $60 \mathrm{~W}$. The HPDL beam was delivered to the work area by means of a $4 \mathrm{~m}$ long, $600 \mu \mathrm{m}$ core diameter optical fibre, the end of which was connected to a $2: 1$ focusing lens assembly. The laser was operated in the continuous wave (CW) mode and produced a multi-mode beam. The HPDL operating parameters were arranged such that the power density of the defocused beam ranged from $0.75-3 \mathrm{~kW} \mathrm{~cm}^{-2}$. The HPDL beam was fired across the surface of the enamel frit by traversing the samples beneath the beam using the $\mathrm{x}$ - and $\mathrm{y}$-axis of a CNC gantry table at a speeds ranging from 180-600 $\mathrm{mm} \mathrm{min}^{-1}$, as depicted in Fig. 2.

So as to study the effects of different process gasses, coaxially blown gas jets of $\mathrm{O}_{2}, \mathrm{Ar} \mathrm{N}_{2}$ and $\mathrm{He}$ were applied at a rate of $81 \mathrm{~min}^{-1}$. In order to examine the effects of the different gasses on the enamel surface glaze of the single-stage ceramic tile grout seal, in particular their influence on the cooling rates of the glaze, the temperatures obtained with the four different process gasses were measured using a Cyclops infrared thermometer (Minolta Ltd.) connected to a PC. As one can see from Fig. 2, the infrared thermometer was arranged such that only the temperatures of the melt pool generated as a result of the HPDL beam impinging on the surface of the enamel frit were measured. The physical characteristics of the cracks observed on the surface of the HPDL generated enamel glazes when using the four different process gasses were determined using an optical profiling system (ProScan) and analysed by means of scanning electron microscopy (SEM).

\section{Results}

The surface morphologies of the glazes produced using the HPDL with the various process gasses were found to contrast markedly depending upon the gas type. Fig. 3 shows a typical optical surface 
view of the HPDL generated enamel glaze when employing (a) $\mathrm{O}_{2}$, (b) Ar, (c) $\mathrm{N}_{2}$ and (d) He process gasses. As is apparent from Fig. 3, the use of $\mathrm{O}_{2}$ as the process gas resulted in surface glazes that exhibited far fewer microcracks and porosities than those generated with either $\mathrm{Ar}, \mathrm{N}_{2}$ or $\mathrm{He}$ process gasses. Moreover, as one can see from Fig 3(a), the enamel glaze generated when using an $\mathrm{O}_{2}$ process gas appears to have very few microcracks and no porosities. Conversely, the enamel glaze generated when He was employed as the process gas can be seen to posses a great many microcracks and numerous porosities (Fig. 3(d)). The enamel glazes produced when using both $\mathrm{Ar}$ and $\mathrm{N}_{2}$ process gasses appear similar (Fig. 3(b) and Fig. 3(c)), although the number of microcracks and porosities present are much less than when a He process gas was used.

The physical characteristics of the cracks in terms of density per square $\mathrm{cm}$, length, depth and width for the four different process gasses at fixed laser operating parameters are given in Table 1. As is evident from Table 1, the crack density obtained when an $\mathrm{O}_{2}$ process gas is employed is very much lower than when using a He process gas, whilst the crack densities obtained when using $\mathrm{Ar}$ and $\mathrm{N}_{2}$ process gasses lie in between the two and are similar to one another. This tendency is repeated to a certain degree for the length, depth and width of the cracks, but not with similar magnitude. It is interesting to note that despite being similar in number, the cracks produced when using the $\mathrm{N}_{2}$ process gas are larger than those seen when Ar was employed. To examine further the effects of process gas on crack formation, the differences in crack formation as a function of process gas and laser parameters are detailed in Fig. 4. As is perhaps to be expected, Fig. 4 shows that the crack density per square $\mathrm{cm}$ is influenced by the laser power employed, increasing as the laser power increases. However, the crack density per square $\mathrm{cm}$ follows the same trend identified in Table 1 regardless of laser power.

The findings of the study to measure the temperatures on the surface of the HPDL generated enamel glaze when the selected process gasses were employed are shown graphically in Fig. 5. As can be seen clearly from Fig. 5, the recorded cooling rate of the enamel glaze surface under a He process gas after the HPDL beam has been removed was slightly faster than that when either Ar or $\mathrm{N}_{2}$ was used as the process gas. But, perhaps more importantly, Fig. 5 shows that a cooling rate considerably slower than those occasioned by the use of either $\mathrm{Ar}, \mathrm{N}_{2}$ or $\mathrm{He}$ as the process gas resulted from employing an $\mathrm{O}_{2}$ process gas. 


\section{Discussion}

An analysis of the results obtained from the experiments conducted showed clearly that the quality of the enamel glazes produced, in terms of porosity and microcracks, was greatly influenced by the type of process gas employed. In particular, the density per square $\mathrm{cm}$ of the cracks resulting from the use of $\mathrm{He}$ as the process gas was found to be greater than when either $\mathrm{Ar}$ or $\mathrm{N}_{2}$ were employed, and much greater than when $\mathrm{O}_{2}$ was used. This marked contrast could be attributed in part to the fact that, due to of its relatively open structure, it is possible for gasses to dissolve molecularly in glasses and, if the gas molecule is small enough, it can diffuse rapidly in a simple glass such as fused silica [15]. Indeed, gasses such as $\mathrm{H}_{2}$ and $\mathrm{O}_{2}$ are known to dissolve molecularly in glass and can also react with the glass network [15]. The use of $\mathrm{O}_{2}$ as the process gas significantly reduced the number of microcracks and porosities within the enamel glaze. This implies that the $\mathrm{O}_{2}$ interacted with the glass network increasing the heat generation and subsequently the fluidity of the melt. In contrast, the He did not interact with the glass network and was consequently trapped within the more viscous melt in the form of bubbles. Indeed, it is believed that mechanism behind the formation of porosities on the surface of the HPDL generated enamel glazes is the outcome of $\mathrm{O}_{2}$ gas escaping from within the melt and disrupting the surface [20]. The $\mathrm{O}_{2}$ is formed naturally and released during the vitrification reaction [21]. If the molten surface of the enamel lacks sufficient fluidity, as is the case when a $\mathrm{He}$ process gas is used, then because of the high viscosity of the melt, the generated $\mathrm{O}_{2}$ can not escape from the molten enamel surface easily. As such, when the $\mathrm{O}_{2}$ eventually does penetrate the melt surface, the resultant porosity is not filled by the flow of the melt since the cooling rate induced by the $\mathrm{He}$ is insufficient to maintain a high enough temperature for an adequate length of time and thus decrease the overall viscosity of the melt [22]. On the other hand, when employing an $\mathrm{O}_{2}$ process gas, the inherent $\mathrm{O}_{2}$ gas bubbles generated during the vitrification of the enamel frit escape from the melt more readily due to its lower viscosity, thus reducing the number of porosities. Indeed, as the cooling rate curves for the HPDL treated enamel glaze surface shown in Fig. 5 indicate, when the HPDL beam was removed, the cooling of the enamel glaze was faster when a He process gas was employed as opposed to an $\mathrm{O}_{2}$ process gas. Therefore, the length of time that the surface of the enamel glaze is of a sufficient fluidity to allow the generated gas bubbles to escape the surface easily is much reduced, resulting in porosities and microcracks. 
The direct effect of the cooling rate of the HPDL generated enamel melt is almost certainly an influential factor governing the resultant surface condition of the enamel glaze itself. A correlation between the cooling rate brought about by the use of a particular process gas and the number and size of the resulting microcracks is clearly evident from a comparison of the cooling rate curves shown in Fig. 5 and the crack details given in Table 1. If the two extremes are considered then it would appear that the much faster cooling rate occasioned by the use of $\mathrm{He}$ as the process gas, rather than $\mathrm{O}_{2}$, results in an enamel glaze with 6-times as many cracks. This is borne out somewhat when one considers that $\mathrm{He}$ is known to effect a faster rate of cooling than $\mathrm{O}_{2}$, as well as $\mathrm{Ar}$ and $\mathrm{N}_{2}[14,16,23]$. Further, a number of workers [24-28] have determined that the 'reactiveness' of $\mathrm{O}_{2}$ means that when it is used as a process gas, exothermic reactions take place which cause additional heating within a melt. It is interesting to note that although $\mathrm{N}_{2}$ is inert, it is known to react very easily with $\mathrm{Fe}$ [29] which is present in reasonable quantities within the enamel frit. Despite this, however, it would appear from Fig. 5 that this reactiveness was not sufficient to reduce the cooling rate of the molten enamel to such a level whereby microcracking was avoided. Clearly, the tendency of the HPDL induced enamel glaze to crack will be reduced if the cooling rate of the molten enamel is reduced. This is principally because a high cooling rate inherently induces thermal stresses which in turn can lead to crack development in order to relieve the generated thermal stresses. This is due to the fact that the enamel has a low thermal conductivity and, as such, during HPDL heating a large thermal gradient between the melt zone and the substrate exists which results in thermal stresses. Additionally, despite the fact that the process of HPDL firing the enamel frit results from a high specific rate of energy which in turn facilitates localised melting of the enamel frit, the fact that a certain amount of the heat will be conducted to sections of the seal where the enamel is already glazed, combined with existence of a relatively cold crushed ceramic tile substrate, means that thermal stresses will be generated. During the heating phase the stresses will be compressive and relieved by plastic deformation, thus precluding crack formation. At high temperatures where the temperature, $T$, is greater than or equal to the melting temperature of the enamel frit, $T_{m}$, the stresses can also be relieved [30-32]. However, during cooling when the temperature falls below $\mathrm{T}_{\mathrm{m}}$, then stresses will accumulate. If the fracture strength of the material is exceeded, then cracking within the melted layer will occur. 
It can be seen from Table 1 that the physical characteristics of the microcracks produced on the surface of the HPDL generated enamel glaze differed depending on the choice of process gas. Table 1 shows clearly that the most severe microcracking occurs when a He process gas is used. But what is worthy of note, however, is the typical occurrence of microcracking within the enamel glaze that was both parallel and perpendicular to the surface when a He process gas was employed (see Fig. 6). Such findings are in accord with the nature of the tensile stresses produced during cooling of the solidifying layer in terms of the glazed layer section thickness. During cooling of a relatively thin glazed layer, the temperature is almost uniform across the section, therefore it only experiences a two-dimensional stress at the surface. But for relatively thick section glazes, as is the case in question here, the temperature gradient across the depth is present along with the gradients at the surface. Consequently the three-dimensional nature of the stresses produces microcracks that are both perpendicular and parallel to the surface $[22,32]$. Such instances of microcracking perpendicular and parallel to the surface were not observed when employing $\mathrm{O}_{2}$, Ar or $\mathrm{N}_{2}$ process gasses, indicating that the stresses induced in the enamel glaze as a result of cooling rate were much less.

\section{Conclusions}

The effects of using $\mathrm{O}_{2}, \mathrm{Ar}, \mathrm{N}_{2}$ and He process gasses during the firing of a vitreous enamel to form a single-stage ceramic tile grout seal with a high power diode laser (HPDL) have been studied. The findings revealed distinct differences in the surface condition of the HPDL generated enamel glaze depending upon the process gas used. The use of $\mathrm{O}_{2}$ as the process gas was seen to result in glazes with far fewer microcracks and porosities than those generated with any of the other three gasses, especially He process gasses. Such differences were found to be due in part to the ability of the smaller $\mathrm{O}_{2}$ gas molecules to dissolve molecularly into the open structure of the HPDL generated enamel glaze and subsequently react with the glass network to increase the fluidity of the melt. Of further influence is the inherent reactiveness of $\mathrm{O}_{2}$ which consequently effects exothermic reactions when it is used as a process gas, thereby causing additional heating within the melt. Both occurrences were seen, in turn, to affect the cooling rate and therefore the tendency of the molten glaze to generate microcracks when cooled. 


\section{Acknowledgements}

The authors would like to express their gratitude to the EPSRC: Process Engineering Group (Grant No. GR/M46068) for their financial support of this work. The authors are also grateful to BNFL, Diomed Ltd., Ferro Group (UK) Ltd. and Ove Arrup \& Partners for their valuable technical assistance. 


\section{References}

1. J. Lawrence, L. Li, J.T. Spencer, Opt. Laser Tech. 30 (1998) 205.

2. J. Lawrence, L. Li, J.T. Spencer, Opt. Laser Tech. 30 (1998) 215.

3. J. Lawrence, PhD Thesis, University of Manchester Institute of Science \& Technology (UMIST), 1999.

4. J. Lawrence, L. Li, R.E. Edwards, A.G. Gale, J. Laser Apps .13 (2001) 222.

5. D.H. Abbott, C.E. Albright, J. Laser Apps. 6 (1994) 69.

6. J. Luo, Z. Cheng, H. Qiang, G. Chen, R. Wang, Proc. of SPIE: Laser Processing of Materials and Industrial Applications, Beijing, China, (1996) 292.

7. C. Bagger, G. Broden, E. Beske, F. Olsen, Int. J. Joining of Mater. 6 (1994) 68.

8. B.G. Chung, S. Rhee, C.H. Lee, Mater. Sci. Eng. A 272 (1999) 357.

9. H. Qiang, Z. Cheng, L. Luo, G. Chen, R. Wang, Proc. of SPIE: Laser Processing of Materials and Industrial Applications, Beijing, China, (1996) 299.

10. T.M.W. Weedon, in: R.C. Crafter, P.J. Oakley (Eds.), Laser Processing in Manufacturing, Chapman \& Hall, London, 1993. pp. 67-90.

11. R.S. Patel, M.Q. Brewster, J. Heat Transfer 112 (1990) 170.

12. R.S. Patel, M.Q. Brewster, J. Thermophys. 5 (1991) 26.

13. D.K.Y. Low, L. Li, A.G. Corfe, Appl. Surf. Sci. 154/155 (2000) 689.

14. D.K.Y. Low, L. Li, A.G. Corfe, J. Eng. Manuf. B 259 (2000) 42.

15. R.H. Doremus, Glass Science, John Wiley \& Sons, New York, 1994, pp. 154-160.

16. G. Allyn, Basic Concepts of Acrylic Emulsion Paint Technology. Rohm \& Haas Company, Philadelphia, 1957, pp. 12-14.

17. P. Haase, MSc Thesis, University of Texas at Austin, 1989.

18. J. Lawrence, L. Li, J.T. Spencer, Mater. Sci. Eng. A 266 (1999) 1067.

19. J. Lawrence, L. Li, J.T. Spencer, Surf. Coatings Tech. 115 (1999) 273. 
20. M.H. Lewis, Glasses and Glass-Ceramics, Chapman \& Hall, London, 1989.

21. P.W. Harben, Raw Materials for the Glass Industry, Metal Bulletin, London, 1977.

22. Z. Lui, PhD Thesis, Liverpool University, 1991.

23. M. Faerber, J. Berkmann, Proc. of SPIE: Laser Processing of Materials and Industrial Applications, Berlin, Germany, 1997, 656.

24. K. Easterling, Introduction to the Physical Metallurgy of Welding, Butterworths-Heinemann, Oxford, 1983, pp. 47-52.

25. D. Bauerle, Laser Processing and Chemistry, Springer-Verlag, Berlin, 1996, pp. 185-191.

26. P.S. Wei, L.R. Chiau, Int. J. Heat Trans. 110 (1988) 918.

27. B.S. Yilbas, M. Sami, J. Phys. D 30 (1997) 1996.

28. D.K.Y. Low, PhD Thesis, University of Manchester Institute of Science \& Technology (UMIST), 2001

29. M.H. Glowacki, J. Phys. D 28 (1995) 2051.

30. R. Sivakumar, B.L. Mordike, J. Surf. Eng. 4 (1988) 127.

31. F.S. Galasso, R. Veltri, Ceram. Bull. 62 (1983) 253.

32. J. Mazumder, Opt. Eng. 30 (1991) 1208. 


\section{List of Figs.}

Fig. 1. Schematic illustration of the single-stage ceramic tile grout seal.

Fig. 2. Schematic illustration of the experimental set-up for the single-stage ceramic tile grout sealing process using the HPDL and the method of temperature monitoring.

Fig. 3. Typical optical surface morphology of the HPDL generated enamel glaze produced with (a) an $\mathrm{O}_{2}$, (b) an $\mathrm{Ar}(\mathrm{c})$ a $\mathrm{N}_{2}$ and (d) a He process gas. $\left(2 \mathrm{~kW} \mathrm{~cm} \mathrm{~cm}^{-2}\right.$ power density, $360 \mathrm{~mm} \mathrm{~min}^{-1}$ traverse speed)

Fig. 4. Relationship between crack density per square $\mathrm{cm}$ and laser power for $\mathrm{O}_{2}, \mathrm{Ar}, \mathrm{N}_{2}$ and $\mathrm{He}$ process gasses. (180 $\mathrm{mm} \mathrm{min}^{-1}$ traverse speed, $1.5 \mathrm{~mm}$ laser beam diameter)

Fig. 5. Best-fit cooling rate curves for the HPDL generated enamel glaze when $\mathrm{O}_{2}, \mathrm{Ar}, \mathrm{N}_{2}$ and $\mathrm{He}$ process gasses were employed.

Fig. 6. Typical SEM cross-sectional view of the HPDL generated enamel glaze produced with a He process gas. ( $2 \mathrm{~kW} \mathrm{~cm}{ }^{-2}$ power density, $180 \mathrm{~mm} \mathrm{~min}^{-1}$ traverse speed) 
Fig. 1

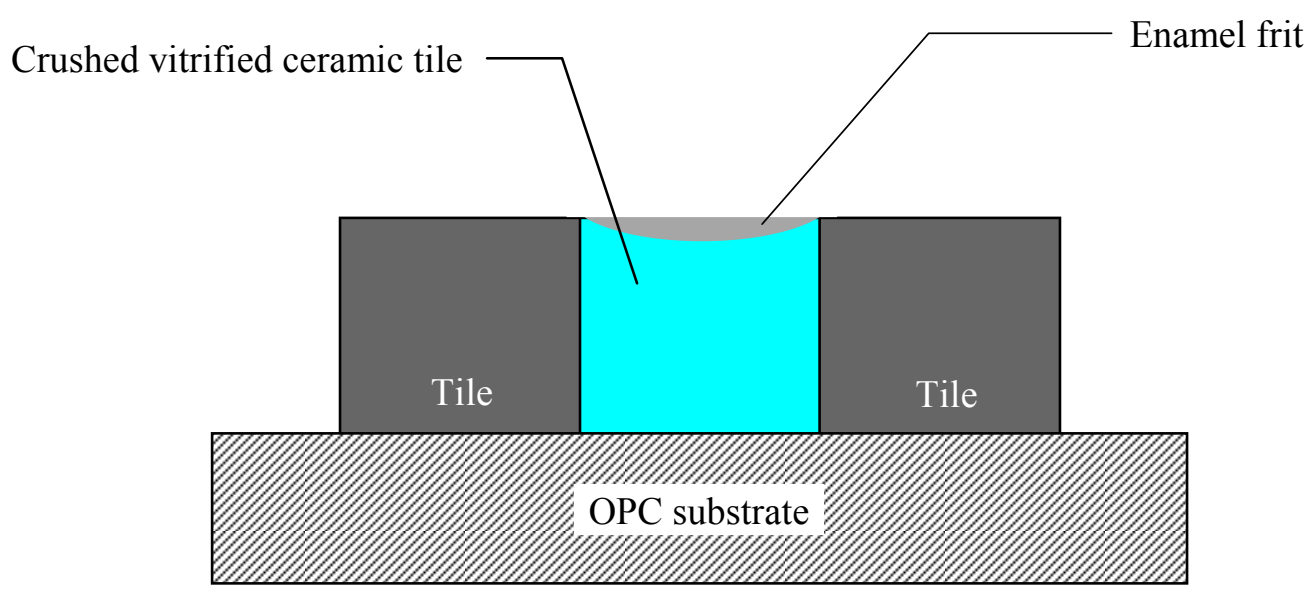


Fig. 2

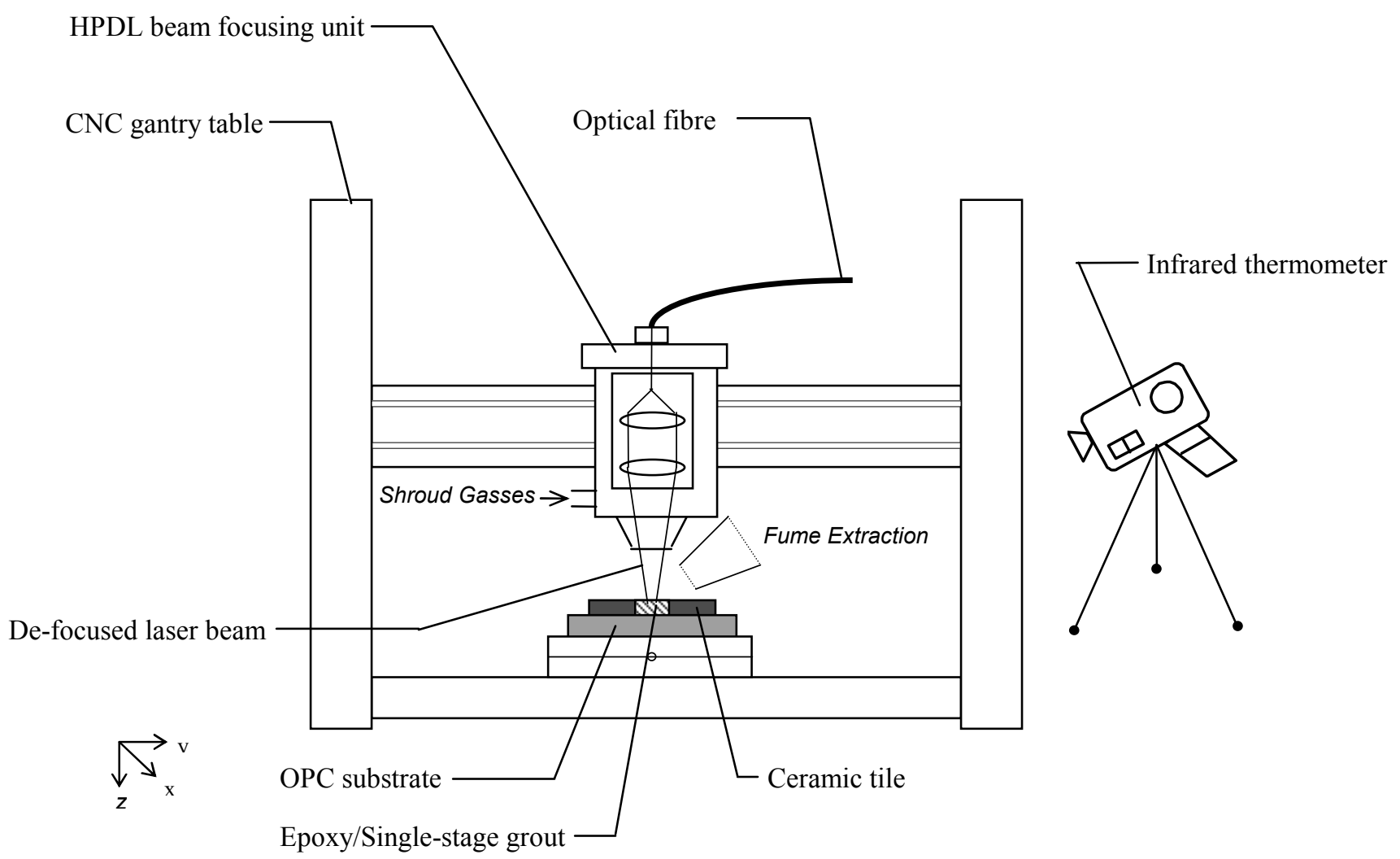


Fig. 3

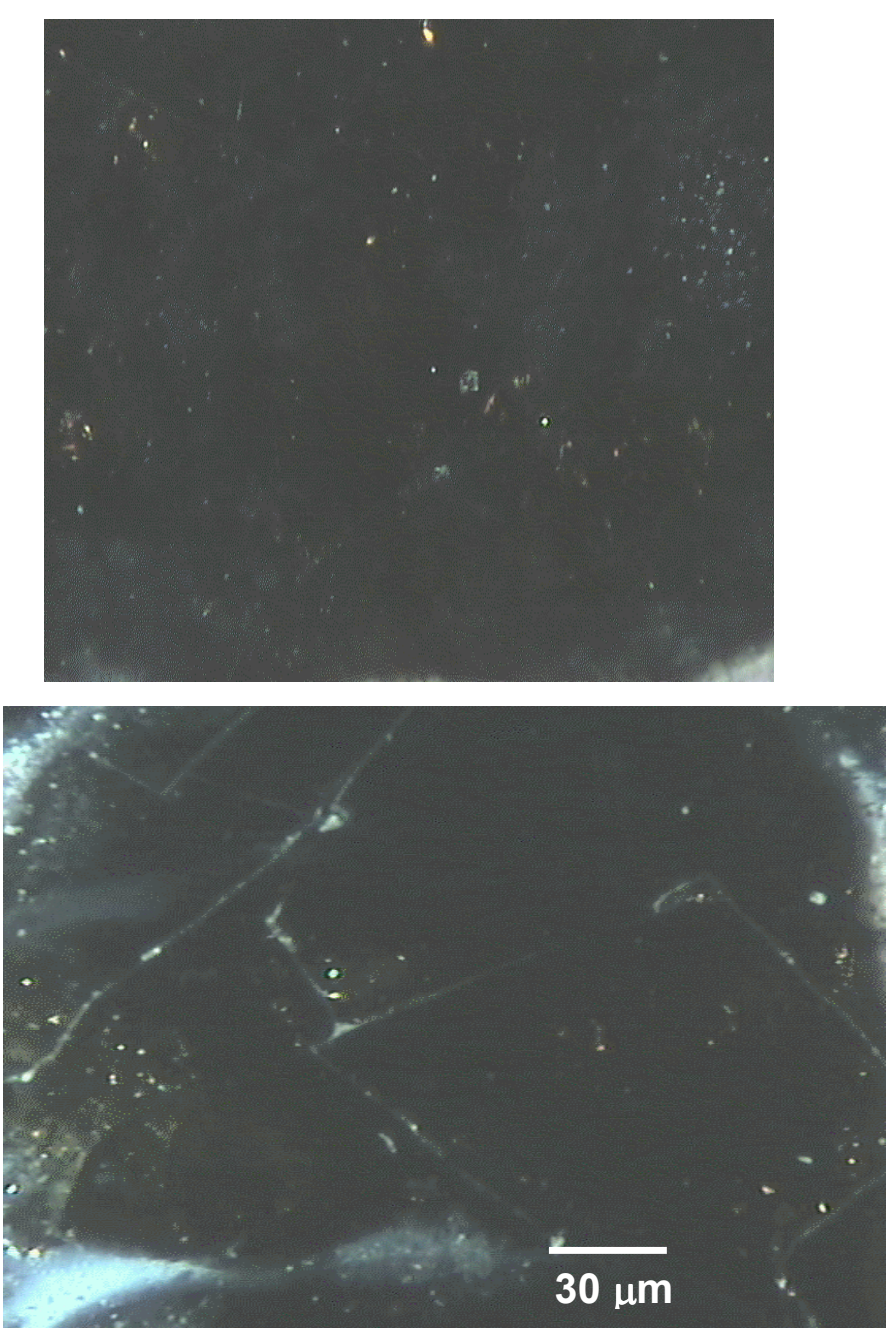

(a)

(b) 

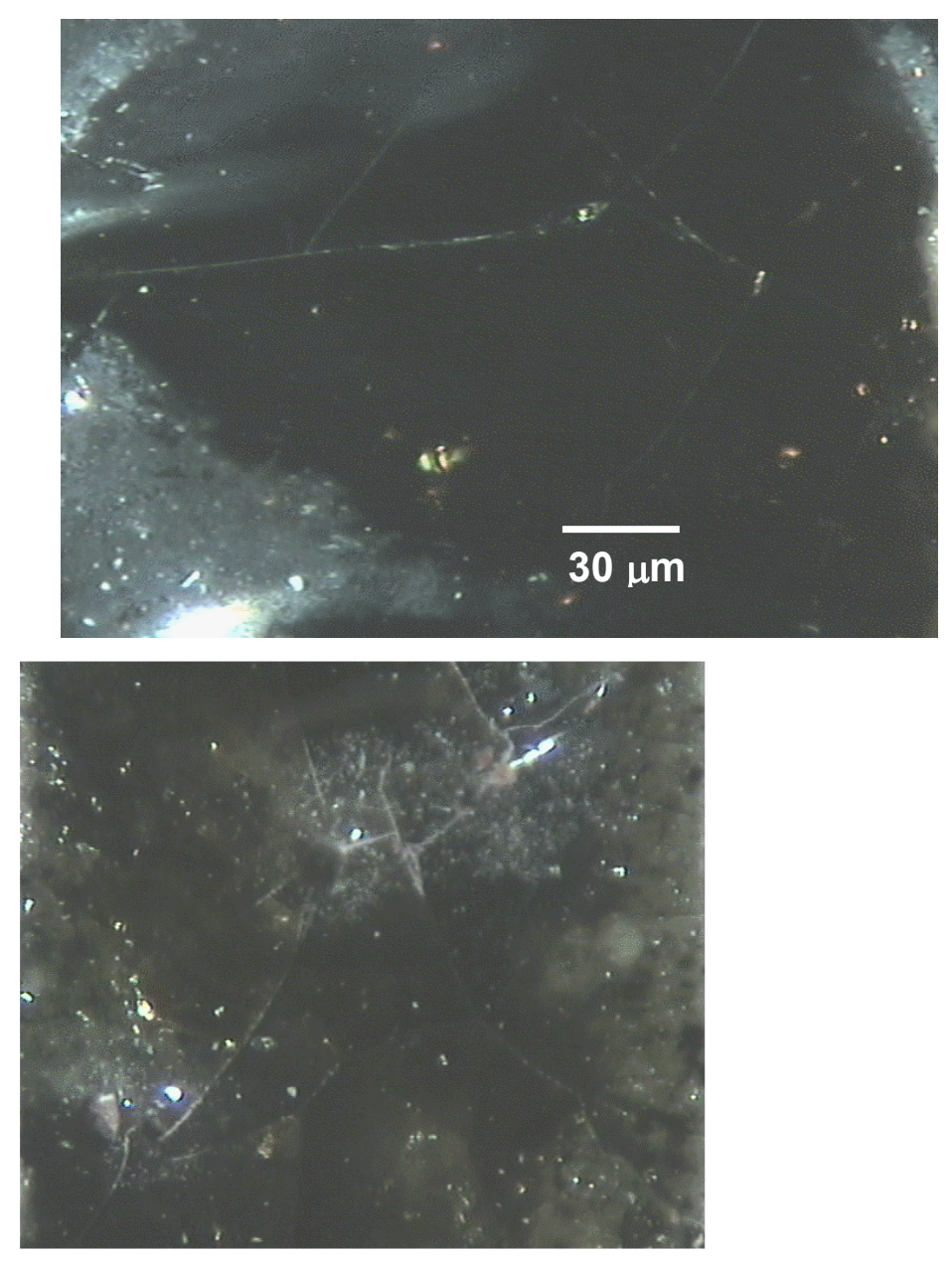

(c)

(d) 
Fig 4

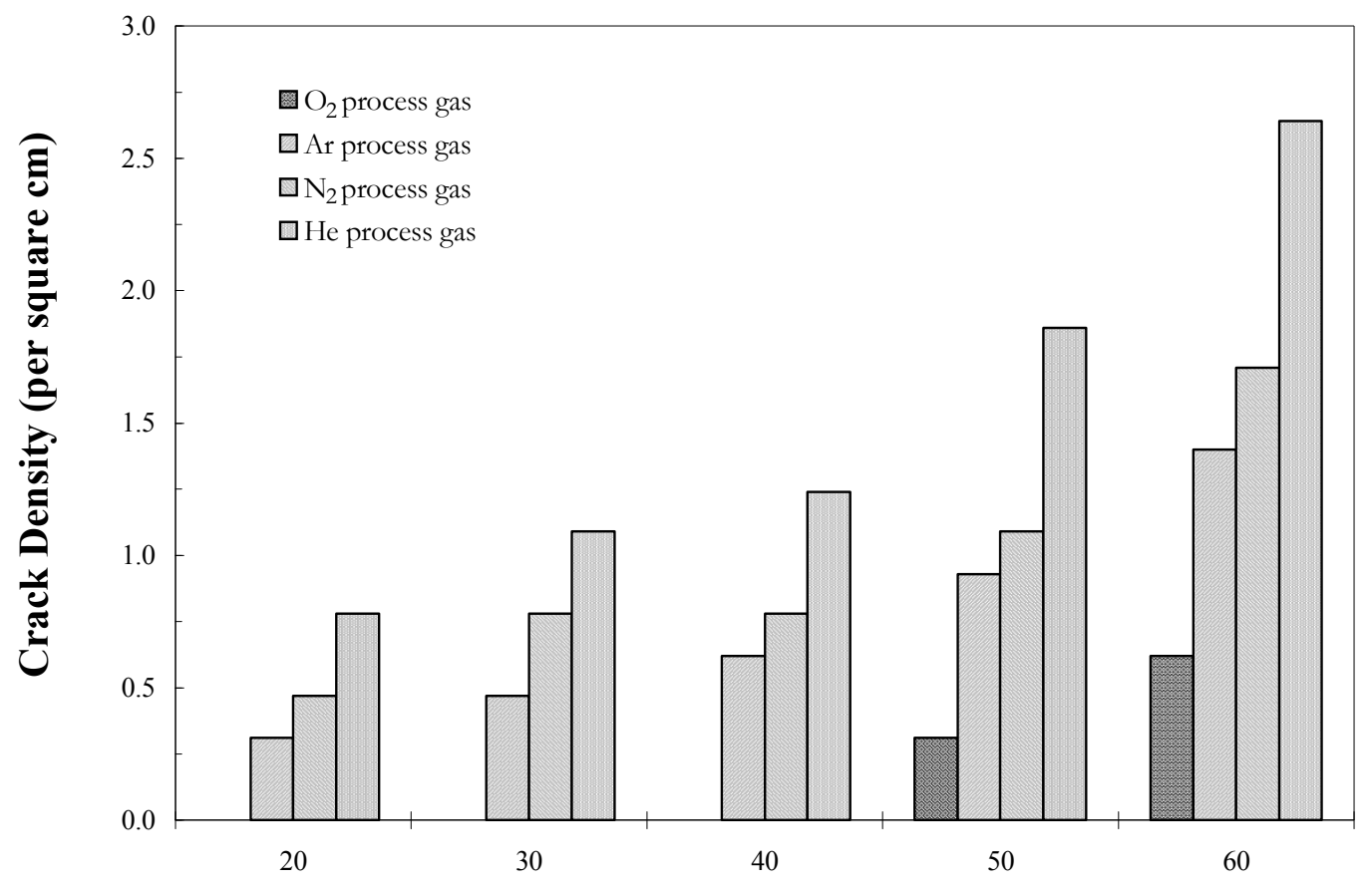


Fig. 5

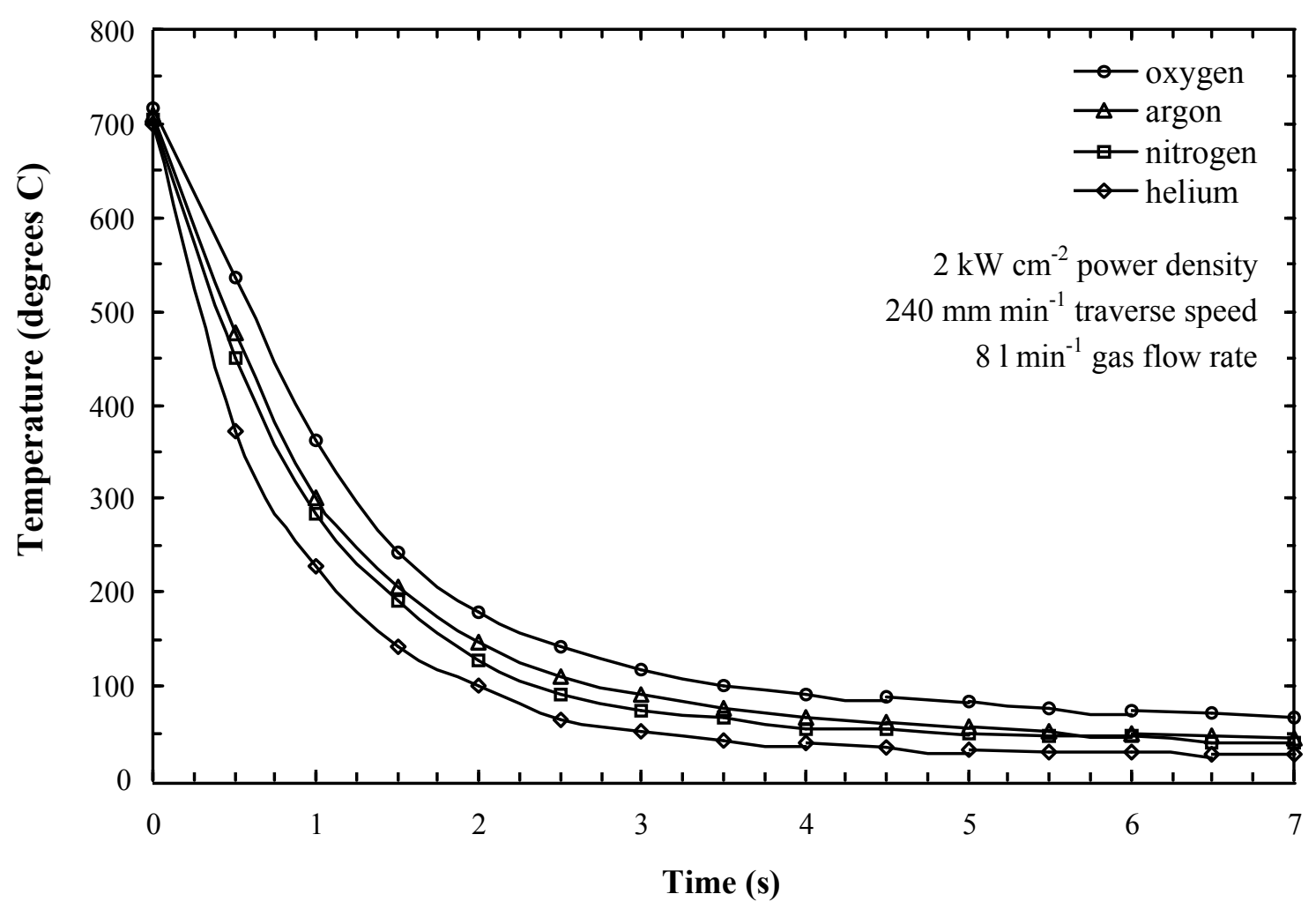


Fig. 6 


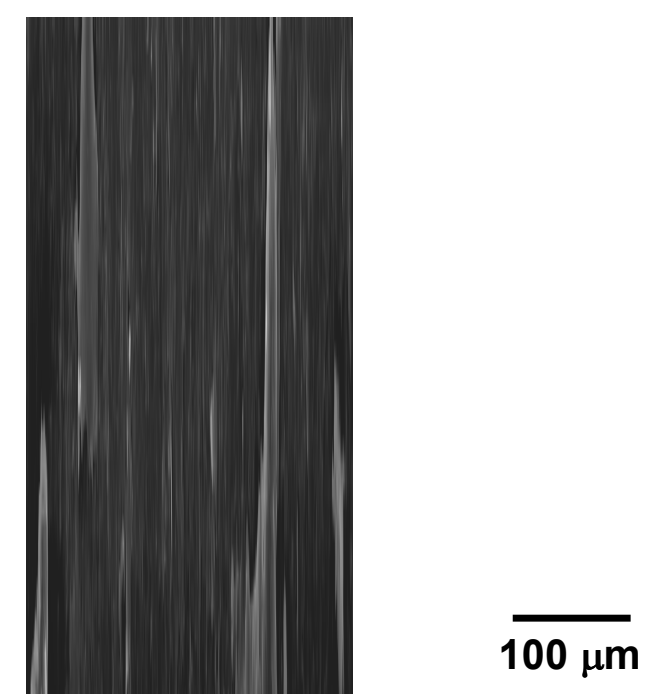




\section{List of Tables.}

Table 1. Physical characteristics of the cracks generated on the HPDL generated enamel glaze when using $\mathrm{O}_{2}, \mathrm{Ar}, \mathrm{N}_{2}$ and He process gasses. $\left(2.5 \mathrm{~kW} \mathrm{~cm}^{-2}\right.$ power density, $180 \mathrm{~mm} \mathrm{~min}^{-1}$ traverse speed) 
Table 1.

\begin{tabular}{lcccc}
\hline \multirow{2}{*}{ Crack Characteristic } & \multicolumn{3}{c}{ Process Gas Type } \\
\cline { 2 - 5 } & $\mathrm{O}_{2}$ & $\mathrm{Ar}$ & $\mathrm{N}_{2}$ & $\mathrm{He}$ \\
\hline Density (per square cm) & 0.31 & 0.93 & 1.09 & 1.86 \\
Average Length $(\mu \mathrm{m})$ & 125 & 125 & 135 & 150 \\
Average Width $(\mu \mathrm{m})$ & 10 & 20 & 25 & 30 \\
Average Depth $(\mu \mathrm{m})$ & 5 & 5 & 10 & 25 \\
\hline
\end{tabular}

